\title{
Outcome after Discontinuation of Proton Pump Inhibitors at a Residential Care Site: Quality Improvement Project
}

\author{
Candy Lee, Anita Lo, Kiran Ubhi, and Michael Milewski
}

\begin{abstract}
Background: Increased prescribing of proton pump inhibitors (PPIs) in the past few decades can be attributed mainly to long-term use of this type of therapy. Recent evidence indicates signals of harm associated with long-term use of PPIs, such as increased risk of Clostridium difficile infection, recurrence of $C$. difficile infection, and fracture. A few studies have assessed the effectiveness of step-down management of patients receiving long-term PPI therapy in ambulatory care settings. However, it is unknown whether PPIs can be discontinued in older people without return of gastrointestinal symptoms.

Objectives: To determine the proportion of residents receiving long-term PPI therapy who were able to discontinue the drug without experiencing gastrointestinal symptoms warranting recommencement of the PPI or initiation of a histamine-2 receptor antagonist.

Methods: The records of residents who had been taking a PPI for longer than 6 months at a single residential care site were audited by one pharmacist to determine the PPI indication. For residents who fit the criteria for discontinuation (no indication for long-term PPI therapy, not currently experiencing gastrointestinal symptoms, no previous trial of PPI discontinuation without success, and no anxiety when medications are discontinued), the pharmacist faxed a recommendation to discontinue PPI therapy without tapering to the physicians' offices. For cases in which the recommendation was accepted, 3 pharmacists followed the residents weekly for 8 weeks to assess whether gastrointestinal symptoms returned.

Results: The pharmacist identified 28 residents who fit the criteria, and the recommendation to discontinue therapy was accepted for 27 . At 8 weeks after the intervention, $19(70 \%)$ of these residents were still asymptomatic and did not require re-initiation of medications to manage their gastrointestinal symptoms.

Conclusions: These results support discontinuation of long-term PPI therapy for older people who fit the criteria for discontinuation. The study provided limited evidence to support the use of tapering. However, tapering can be used to identify the lowest effective dose and may increase patient comfort with deprescribing. Further research is needed to determine the effects of and best approaches to PPI discontinuation in older populations.
\end{abstract}

\section{RÉSUMÉ}

Contexte : L'augmentation des prescriptions d'inhibiteurs de la pompe à protons (IPP) au cours des dernières décennies peut être attribuée principalement à l'utilisation à long terme de ce type de traitement. Des données récentes indiquent que l'utilisation à long terme des IPP comporte des dangers potentiels, notamment une augmentation du risque d'infection par Clostridium difficile, de récurrence de cette infection et de fracture. Quelques études ont évalué l'efficacité de la déprescription des IPP chez des patients recevant un traitement prolongé en milieu ambulatoire. Cependant, on ne sait pas s'il est possible de cesser l'utilisation d'IPP chez le patient âgé tout en évitant la réapparition de symptômes gastro-intestinaux.

Objectif : Déterminer la proportion de résidents pour qui l'on a été en mesure de cesser le traitement à long terme par IPP sans qu’apparaissent des symptômes gastro-intestinaux nécessitant la reprise du traitement par IPP ou l'amorce d'un traitement par antagoniste des récepteurs $\mathrm{H}_{2}$ de l'histamine.

Méthodes : L'étude a eu lieu dans un seul centre d'hébergement et de soins de longue durée. Un pharmacien y a analysé les dossiers médicaux des résidents qui prenaient des IPP depuis plus de six mois afin de déterminer l'indication du médicament. Pour les résidents répondant aux critères de déprescription (aucune indication pour un traitement d'entretien, aucun symptôme gastro-intestinal à l'heure actuelle, aucune tentative antérieure de déprescrire un IPP en vain et aucune réaction anxieuse à l'arrêt de traitements), le pharmacien a envoyé par télécopieur aux bureaux des médecins un document recommandant l'interruption du traitement par IPP sans posologie dégressive. Dans les cas où la recommandation a été acceptée, trois pharmaciens ont suivi hebdomadairement les résidents pendant huit semaines afin de vérifier si des symptômes gastro-intestinaux réapparaissaient.

Résultats : Le pharmacien a repéré 28 résidents répondant aux critères et la recommandation d'interruption de traitement a été acceptée pour 27 d'entre eux. Huit semaines après l'intervention, 19 (70 \%) de ces résidents étaient toujours asymptomatiques et n'ont pas eu besoin qu'on leur prescrive de nouveau des médicaments pour traiter des symptômes gastro-intestinaux.

Conclusions : Ces résultats viennent appuyer l'interruption du traitement à long terme d'IPP chez le patient âgé qui répond aux critères d'interruption. 
Keywords: proton pump inhibitors, residential care, elderly population, polypharmacy, deprescribing, discontinuation

Can J Hosp Pharm. 2017;70(3):215-23
Cette étude n'a founi que peu de preuves qui appuient le recours à la posologie dégressive. Cependant, celle-ci peut servir à déterminer quelle est la plus faible dose efficace et elle peut aider les patients à être plus à l'aise avec l'interruption du traitement. Des recherches plus approfondies sont nécessaires pour préciser les conséquences de l'arrêt des IPP chez les personnes âgées et la meilleure approche à cette fin.

Mots clés : inhibiteurs de la pompe à protons, soins en établissement, personnes âgées, polypharmacie, déprescription, interruption

\section{INTRODUCTION}

$\mathrm{I}^{\mathrm{n}}$ ncreased prescribing of proton pump inhibitors (PPIs) in the past few decades can be attributed mainly to their long-term use. ${ }^{1}$ Certain conditions, such as Barrett esophagus, severe esophagitis, and long-term therapy with nonsteroidal antiinflammatory drugs (NSAIDs), qualify patients for indefinite use of PPIs; however, for other indications, such as gastroesophageal reflux disease (GERD), reflux esophagitis, Helicobacter pylori infection, and peptic ulcer, PPI therapy is recommended for only 2 to 12 weeks. ${ }^{1}$ Previous literature has indicated overutilization of PPIs for patients in both hospital and community settings ${ }^{2-6}$ and a lack of routine symptom re-evaluation in ambulatory care settings. ${ }^{7}$ For example, Heidelbaugh and others ${ }^{7}$ found that $36.1 \%$ of 946 patients taking PPIs in an ambulatory care setting had no documented appropriate indication for PPI therapy. In addition, recent evidence has indicated signals of harm associated with long-term use of PPIs; in particular, observational studies have identified possible associations between PPI use and increased risk of clinically important adverse events, such as Clostridium difficile infection, recurrent $C$. difficile infection, ${ }^{8-11}$ and fracture. ${ }^{12}$ In several meta-analyses, ${ }^{8-11}$ involving between 23 and 47 studies in community and hospital settings (with high heterogeneity among the studies in each meta-analysis), the odds ratios (ORs) for $C$. difficile infection among PPI users relative to non-users ranged from 1.65 to 2.15 . Kwok and others ${ }^{10}$ also found a significant risk of recurrent $C$. difficile infection among PPI users (OR 2.51) in their meta-analysis. A systematic review of 10 observational studies found that PPI users had a higher risk of hip fracture (OR 1.25) and vertebral fracture (OR 1.5) than non-users. ${ }^{11}$

Lack of symptom re-evaluation and the potential for longterm adverse effects of certain medications contribute to the concept of "polypharmacy". According to one health authority, polypharmacy is defined as the "administration of more medications than clinically required or appropriate, [where the] theoretical benefits of multiple medications are outweighed by the adverse effects of the medications", increasing the risk of "experiencing illness and unintended harm". ${ }^{13}$ Polypharmacy is a particular concern for older people ( $>65$ years of age), because they have more comorbid chronic diseases necessitating more medications. In older people, polypharmacy increases the likelihood of placement in a nursing home, impairment of mobility, hospitalization, and death. ${ }^{14-16}$ The older population is also more likely than the younger population to experience adverse drug events. ${ }^{14-16}$ It has been estimated that adverse drugs events are common in community-dwelling older patients, with a prevalence of up to $35 \% .{ }^{17}$ Furthermore, adverse drug events are responsible for up to $30 \%$ of hospital admissions among older patients. ${ }^{18}$ As a result, there has been increased awareness about polypharmacy in the older population. For example, previous studies have concluded that it is possible to follow a general algorithm to discontinue medications and reduce polypharmacy in older people. ${ }^{19,20}$ Garfinkel and Mangin ${ }^{20}$ applied the Good Palliative-Geriatric Practice algorithm to 70 community-dwelling patients with a mean age of 80 years. After 19 months, 58\% of all medications were discontinued, with only $2 \%$ of these medications restarted later.

Although there are perceived benefits to stopping unnecessary PPI prescribing, it is difficult to discontinue these drugs in the ambulatory setting. Previous literature regarding PPI discontinuation reported success rates of $14 \%$ to $64 \%$ in community-based patients. ${ }^{21-25}$ It is unknown whether PPIs can be safely discontinued in older people without return of gastrointestinal symptoms. Linksy and others ${ }^{26}$ performed a retrospective study looking at characteristics of PPI discontinuation in residential care settings, and concluded that many residents can have their PPI therapy discontinued without issues. Thompson and others ${ }^{27}$ found that PPI prescribing at 3 residential care sites could be reduced by means of a deprescribing algorithm. However, they did not assess rates of symptom relapse following PPI discontinuation. The aim of the current study was to determine whether long-term PPI therapy could be safely discontinued for residents at a residential care site without recurrence of gastrointestinal symptoms.

\section{METHODS}

This study was carried out from September 21, 2015, to May 30, 2016, at Baillie House in Ridge Meadows Hospital, Maple Ridge, British Columbia. Baillie House is a 150-bed residential care facility, operated by the Fraser Health Authority (FHA), that offers publicly subsidized residences. The facility uses an "automated multi-dose medication system" for oral solid medications. For each resident, the FHA's pharmacy drug distribution centre packages medications into sachets according 
to medication administration time; the sachets are then attached sequentially as a strip. These patient-specific strips are packaged and delivered daily to Baillie House. Medications are administered by nursing staff (registered nurses or licensed practical nurses) on the units. A data access agreement for the current study was signed by the corresponding author and accepted by the FHA. Ethics approval was not obtained, because the FHA deemed the study to be a quality improvement project. The FHA also waived the need for documented informed consent of participants. However, residents and/or caregivers were made aware of the initiative where possible and could choose not to participate if they wished.

\section{Participants}

Pantoprazole and esomeprazole, the 2 PPIs available on the FHA formulary, were used as initial search terms in the FHA's electronic medical records to identify residents who were taking PPIs as of March 18, 2016. Any resident taking a PPI other than pantoprazole or esomeprazole was excluded. Residents' medical records were audited for PPI indication if they had been taking pantoprazole or esomeprazole for longer than 6 months. No resident or caregiver declined to participate.

\section{Data Collection}

For each resident eligible for inclusion, a pharmacist (C.L.) at Ridge Meadows Hospital manually reviewed the electronic medical record and physical chart (including notes written by nurses, physician, and pharmacists) in an attempt to ascertain the resident's indication for PPI therapy. The pharmacist followed the PPI deprescribing algorithm of the Ontario Pharmacy Research Collaboration (OPEN) to exclude residents for whom PPI discontinuation would be inappropriate. ${ }^{28}$ Residents were excluded if they had documentation of previous peptic ulcer with concurrent antiplatelet therapy or if they were on long-term, regularly scheduled NSAID therapy. Following indication auditing, medical records and clinical notes were further utilized to identify residents currently experiencing gastrointestinal symptoms (heartburn, emesis, indigestion, epigastric pain, loss of appetite, agitation, or weight loss), residents with a previous trial of PPI discontinuation that was unsuccessful, and residents who became anxious when medications were discontinued; these residents were also deemed unsuitable for PPI discontinuation. Where possible, the pharmacist consulted nursing staff and/or the residents themselves to assess for the presence of current gastrointestinal symptoms and to identify residents who became anxious when medications were discontinued. Figure 1 summarizes the selection of residents meeting the criteria for PPI discontinuation.

\section{Intervention}

Once the study sample was identified, the pharmacist sent recommendations for PPI discontinuation without tapering by fax to the outpatient clinic of each resident's most responsible physician. "Discontinuation without tapering" was defined as discontinuation of the PPI at a single point in time, without any prior decrease in dosage. If no response was received from the physician within 1 week, the pharmacist sent the same recommendation to the medical director of the residential care facility (M.M.).

The intervention was initiated as follows. Once each physician's response was received at Baillie House, the PPI was discontinued, tapered, or changed to histamine- 2 receptor antagonist (H2RA) according to physician preference. PPI discontinuation was discussed with the residents and/or their caregivers where possible, so that they would know to report new symptoms or changes in symptoms to staff. The regular care process at this facility is for nursing staff to follow a symptom action plan for up to $48 \mathrm{~h}$ for certain conditions, including gastric discomfort. Nursing staff can give aluminum magnesium hydroxide (antacid) 15 to $30 \mathrm{~mL}$ orally every $4 \mathrm{~h}$ as needed. If this medication is used, it is documented on the medication administration record. If symptoms persist longer than $48 \mathrm{~h}$, nursing staff are instructed to contact the physician for further management.

Following the intervention, residents were actively followed for 8 weeks, at weekly intervals, by 3 pharmacists (C.L., A.L., K.U.) to assess for adverse events related to discontinuation of the PPI. Adverse events were defined as heartburn, emesis, indigestion, epigastric pain, loss of appetite, agitation, or weight loss. Agitation was determined by the use of as-needed antipsychotic medications. Weight loss was defined as any change greater than $5 \mathrm{~kg}$. Pharmacists' assessments for adverse events included verbally consulting with care aides, registered nurses, licensed practical nurses, or residents to assess for new symptoms or changes in symptoms; checking each resident's medication administration record to see whether any as-needed antacids or antipsychotics had been given; reviewing nursing notes, physician notes, and pharmacist notes for documented gastrointestinal symptoms; and comparing residents' monthly weight (as documented by nursing staff). In addition, new symptoms or changes in symptoms were discussed with nurses, physicians, and residents during rounds and care conferences. If a pharmacist identified the presence of gastrointestinal symptoms necessitating PPI re-initiation, it was up to the discretion of the pharmacist to make the appropriate recommendation (by telephone or fax) to the most responsible physician or the medical director.

\section{Primary Outcome}

The primary outcome was the proportion of residents who had been taking PPIs for more than 6 months who were able to discontinue PPI therapy without experiencing gastrointestinal symptoms severe enough to warrant recommencement of PPIs or initiation of H2RAs. 


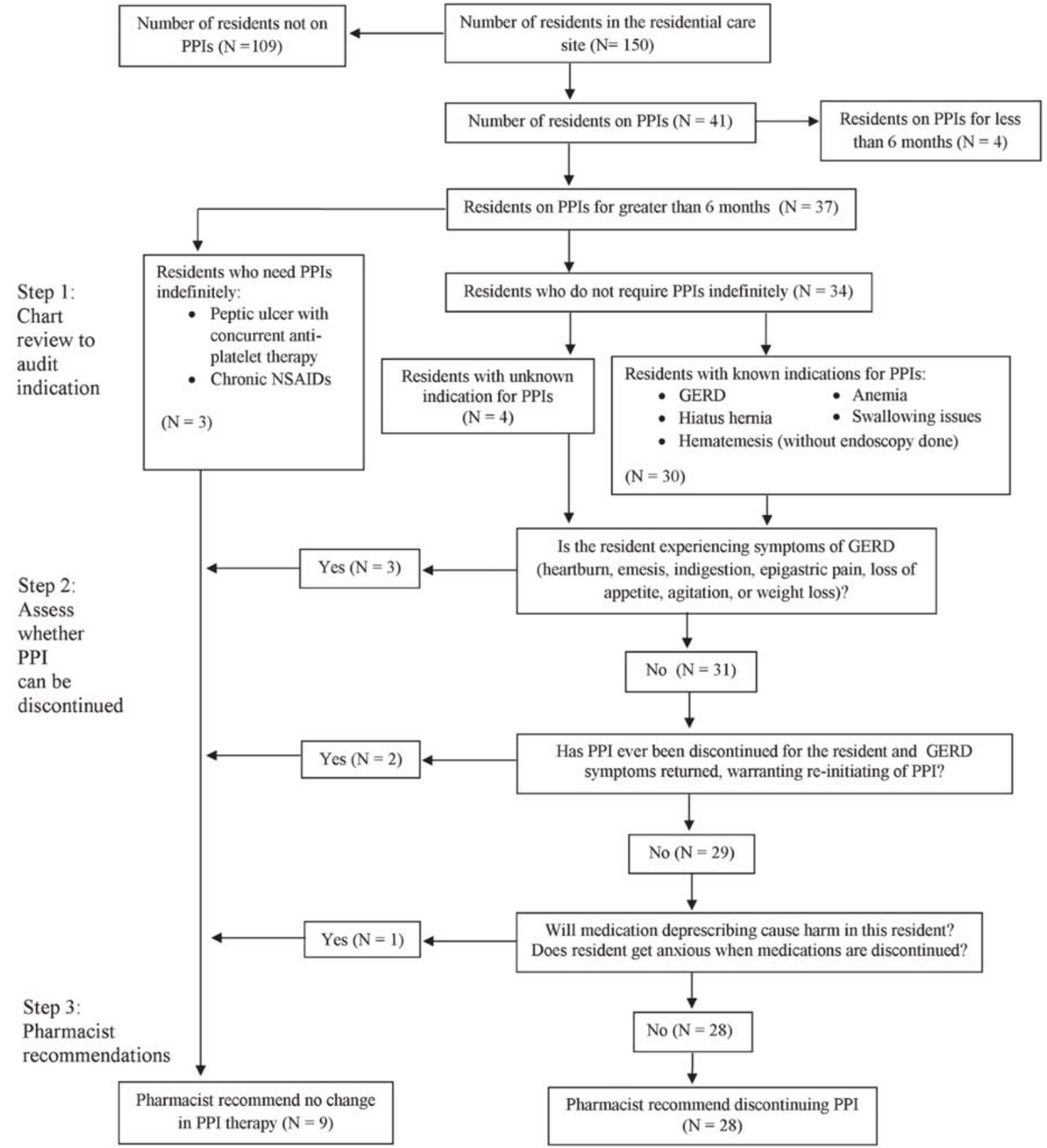

Figure 1. Protocol for evaluating residents for discontinuation of proton pump inhibitor (PPI) therapy. GERD = gastroesophageal reflux disease, NSAID = nonsteroidal anti-inflammatory drug. 


\section{Statistical Analyses}

Descriptive analysis and $\chi^{2}$ tests were used for demographic variables. Continuous variables are expressed as means with standard deviations.

Table 1. Reasons for Not Meeting PPI Discontinuation Criteria

\begin{tabular}{|c|c|c|}
\hline Reason & No. (\%) & $\begin{array}{l}\text { f Residents } \\
=9)\end{array}$ \\
\hline $\begin{array}{l}\text { Previous peptic ulcer, currently on } \\
\text { antiplatelet medication }\end{array}$ & 2 & (22) \\
\hline Current long-term NSAID use & 1 & $(11)$ \\
\hline Currently experiencing GERD symptoms & 3 & (33) \\
\hline $\begin{array}{l}\text { Previous unsuccessful trial of PPI } \\
\text { discontinuation }\end{array}$ & 2 & $(22)$ \\
\hline $\begin{array}{l}\text { Anxiety develops when medications } \\
\text { are discontinued }\end{array}$ & 1 & $(11)$ \\
\hline
\end{tabular}

\section{RESULTS}

A total of 37 residents had been taking PPIs for longer than 6 months, of whom 28 met the criteria for discontinuation (Figure 1). The 9 excluded residents consisted of 3 who had been identified as needing PPIs indefinitely, 3 who were currently experiencing gastrointestinal symptoms, 2 with previously trials of PPI discontinuation without success, and 1 who had anxiety when medications were discontinued (Table 1). Baseline characteristics differed slightly but not significantly between residents who met and did not meet the criteria for discontinuation (Table 2 ): mean age $80 \pm 11.8$ years versus $79 \pm 12.3$ years $(p=0.74)$; female sex 64\% (18/28) versus 89\% (8/9) ( $p=0.23)$; mean duration of treatment $27 \pm 15.3$ months versus $46 \pm 28.5$ months ( $p=0.08)$; and 46\% (13/28) versus 44\% (4/9) with dementia $(p>0.99)$. With regard to dosing, most residents were receiving pantoprazole $40 \mathrm{mg} /$ day or esomeprazole $40 \mathrm{mg} /$ day: $93 \%(26 / 28)$ and $78 \%(7 / 9)$, respectively.

Table 2. Baseline Characteristics of Residents in a Study of PPI Discontinuation in a Residential Care Facility

\begin{tabular}{|c|c|c|c|}
\hline \multirow[b]{2}{*}{ Characteristic } & \multicolumn{2}{|c|}{ No. $(\%)$ of Residents* } & \multirow[b]{2}{*}{$p$ Value } \\
\hline & $\begin{array}{c}\text { Fit Criteria for } \\
\text { Discontinuation } \\
(n=28)\end{array}$ & $\begin{array}{l}\text { Did Not Fit Criteria } \\
\text { for Discontinuation } \\
\qquad(n=9)\end{array}$ & \\
\hline Age (years) (mean \pm SD) & $80 \pm 11.8$ & $79 \pm 12.3$ & 0.74 \\
\hline \multicolumn{4}{|l|}{ Sex } \\
\hline Male & $10(36)$ & $1(11)$ & 0.23 \\
\hline Female & $18(64)$ & $8(89)$ & 0.23 \\
\hline $\begin{array}{l}\text { Duration of treatment (months) } \\
\text { (mean } \pm \text { SD) }\end{array}$ & $27 \pm 15.3$ & $46 \pm 28.5$ & 0.08 \\
\hline Pantoprazole & $14(50)$ & $7(78)$ & 0.25 \\
\hline 20 mg daily & 1 & 0 & \\
\hline 40 mg daily & 13 & 6 & \\
\hline 40 mg twice daily & 0 & 1 & \\
\hline Esomeprazole & $14(50)$ & $2(22)$ & 0.25 \\
\hline 40 mg daily & 13 & 1 & \\
\hline 40 mg twice daily & 1 & 1 & \\
\hline \multicolumn{4}{|l|}{ Reason for PPI } \\
\hline Peptic ulcer prophylaxis & $0 \quad(0)$ & $4(44)$ & 0.002 \\
\hline GERD & $13(46)$ & $3(33)$ & 0.70 \\
\hline GERD and hiatus hernia & $3(11)$ & $0 \quad(0)$ & 0.56 \\
\hline Hiatus hernia & $1 \quad(4)$ & $0 \quad(0)$ & $>0.99$ \\
\hline Emesis & $6(21)$ & $1 \quad(11)$ & 0.66 \\
\hline Unexplained anemia & $1 \quad(4)$ & $0 \quad(0)$ & $>0.99$ \\
\hline Swallowing issues & $1 \quad(4)$ & $0 \quad(0)$ & $>0.99$ \\
\hline Unknown & $3(11)$ & $1(11)$ & $>0.99$ \\
\hline Concurrent antimotility agents & $3(11)$ & $4(44)$ & 0.045 \\
\hline $\begin{array}{l}\text { Concurrent therapy with } \\
\text { anticoagulant, antiplatelet } \\
\text { agent, or NSAID }\end{array}$ & $12(43)$ & $6 \quad(67)$ & 0.27 \\
\hline Previous endoscopy & $4(14)$ & $0 \quad(0)$ & 0.55 \\
\hline Dementia & $13(46)$ & $4(44)$ & $>0.99$ \\
\hline
\end{tabular}


The 28 recommendations for PPI discontinuation were faxed to the most responsible physicians' offices on March 29, 2016. In 22 cases, the recommendation to discontinue PPI without tapering was accepted promptly by the most responsible physician. For 1 resident, the most responsible physician preferred not to discontinue the PPI, for unknown reasons; this physician declined the option for the resident to participate. For another resident, the physician preferred to taper the PPI (Figure 2). For 4 residents, the physician did not respond within 1 week, and the medical director was contacted on April 4, 2016. The medical director accepted the pharmacist's recommendation for 1 resident and changed 3 residents to H2RA therapy because of preference (Figure 2). In total, PPI therapy was discontinued for 27 residents: without tapering, with tapering, or with a switch to H2RA therapy.

Following the intervention, between April 5 and May 30, 2016, each participating resident was followed at weekly intervals for 8 weeks by 1 of 3 pharmacists, to assess for symptom recurrence. The residents were randomly assigned, with the 3 pharmacists following 11, 9, and 7 residents, respectively.

For $3(11 \%)$ of the participants whose PPI was discontinued, it was not possible to establish the indication for PPI therapy. Most of the other participants with PPI discontinuation had GERD or hiatus hernia as the indication for their PPI (17 [63\%]). The remaining 7 participants (26\%) were originally started on PPIs with a non-approved indication (emesis, swallowing issues, or anemia) (Table 2).
Table 3. Outcome 8 Weeks after Discontinuation of PPI

\begin{tabular}{lcc} 
Outcome & \multicolumn{2}{c}{ No. $(\%)$ of } \\
Participants $(\boldsymbol{n}=\mathbf{2 7})$
\end{tabular}

H2RA = histamine-2 receptor antagonist, $\mathrm{PPI}=$ proton pump inhibitor.

Eight weeks after discontinuing PPI therapy, 19 (70\%) of the 27 participants with PPI discontinuation were still symptomfree and did not require PPI re-initiation (Table 3). PPIs were restarted for 3 participants (11\%): after 9 days because of heartburn in one case, after 25 days because of reflux in one case, and after 27 days because of coffee ground emesis in one case. For one participant (4\%), H2RA therapy was started for vomiting after 33 days off PPI therapy. Of these 4 participants for whom PPI discontinuation was unsuccessful, the mean time to restarting a PPI or initiating an H2RA was 23.5 days.

The remaining 4 study participants (15\%) died before the end of the study period, as did one (11\%) of the 9 residents who did not fit the criteria for PPI discontinuation $(p>0.99)$. This is consistent with the typical number of deaths at this residential care facility. It is not standard practice at this residential care site to perform an autopsy after death, so the causes of death are unknown.

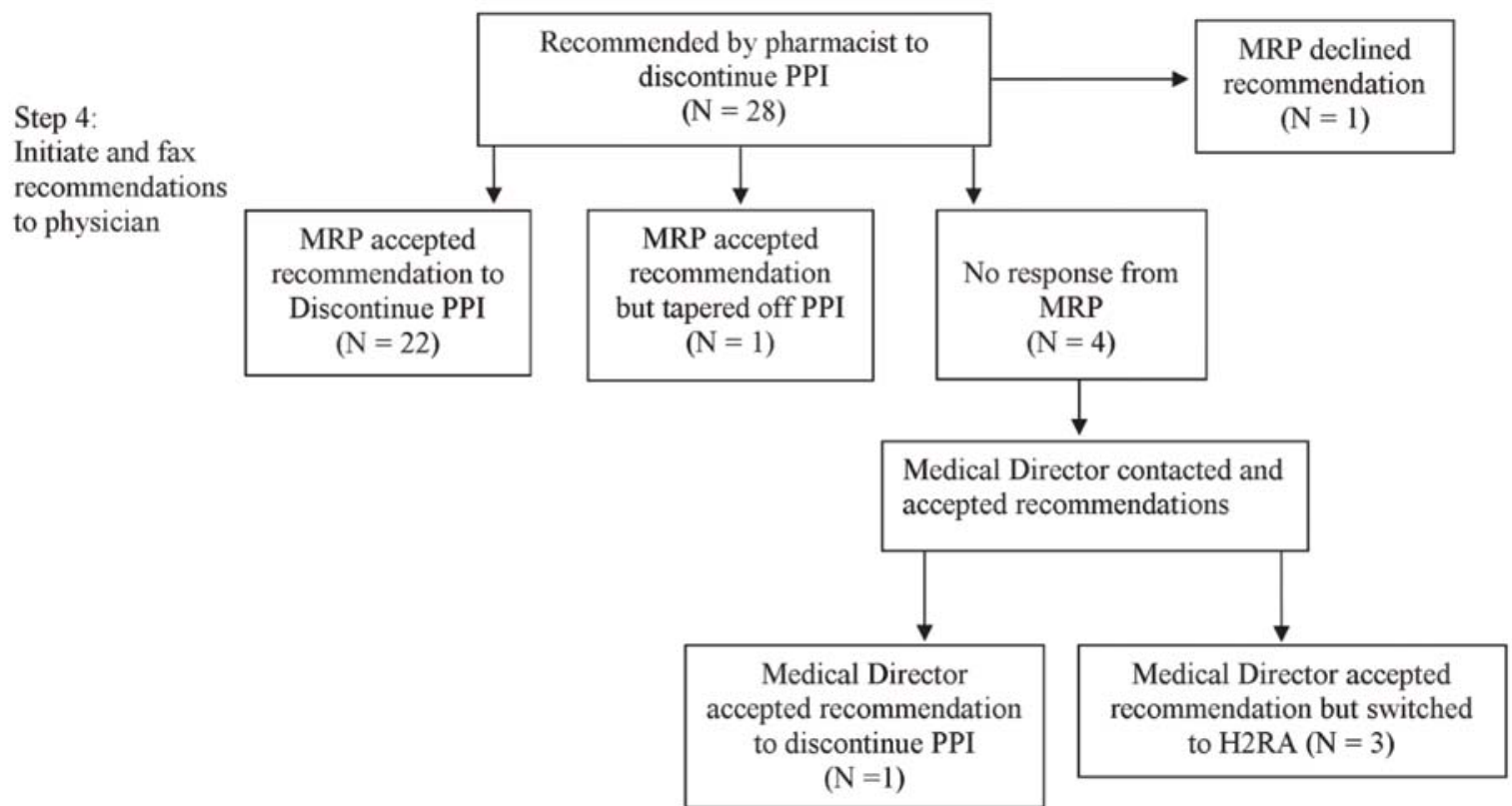

Figure 2. Summary of study process and main outcomes. H2RA = histamine-2 receptor antagonist, $\mathrm{MRP}=$ most responsible physician, $\mathrm{PPI}=$ proton pump inhibitor 


\section{DISCUSSION}

Long-term use of PPIs has been associated with $C$. difficile infection, recurrent $C$. difficile infection, and fracture. ${ }^{2-6}$ The older population is at greater risk of adverse drug events because many older people are taking multiple medications. ${ }^{14-16} \mathrm{PPIs}$ were listed in the Screening Tool of Older Person's Prescriptions (STOPP), a screening tool designed to assess for potentially inappropriate drugs in the elderly population. ${ }^{19}$ Currently, deprescribing guidance is limited, with clinicians reporting difficulty in weighing the harms against the benefits of continuing or stopping medications. ${ }^{29}$ PPIs were selected by OPEN as 1 of 3 medications for development of a deprescribing guideline to "support health care professionals taper or stop potentially inappropriate medications that may be causing harm or no longer providing a benefit as well as monitoring for potential adverse withdrawal effects" ${ }^{28}$ At the time of the current study (late 2015 to early 2016), the OPEN algorithm had not yet been published. Since then, the methodology for developing the OPEN deprescribing algorithms has been published (in August 2016). ${ }^{29}$ Thompson and others ${ }^{27}$ implemented and evaluated the OPEN PPI deprescribing algorithm at 3 residential care sites and found that it could decrease PPI prescribing. We used the algorithm to assess whether residents fit the criteria for discontinuation and then monitored those with PPI discontinuation to assess for recurrent gastrointestinal symptoms that would warrant re-initiation of the PPI.

This study investigated the outcomes of discontinuing PPIs without tapering among residents on long-term PPI therapy (over 6 months) at Baillie House, a residential care facility in Maple Ridge, affiliated with FHA. To our knowledge, this project was the first such study conducted specifically at a residential care site.

After 8 weeks, PPI discontinuation was deemed successful for $70 \%$ of the study population. There are a few reasons why this study achieved a higher success rate than previous studies. Previous studies, which reported discontinuation success rates of only $14 \%$ to $64 \%$, were conducted in primary care or community patients. ${ }^{21-25}$ In contrast, the current study focused on a residential care site, and the mean age of the study population was 80 years, older than the mean age in previous studies. Previous studies found that it was easier to discontinue PPIs in older patients because their GERD symptoms were subjectively less severe than those of younger patients. ${ }^{25,30}$ Additionally, symptom perception among older patients was weaker than among younger patients. ${ }^{25,30} \mathrm{~A}$ certain proportion of residents in the current study had dementia, which might have interfered with their ability to self-report gastrointestinal symptoms, especially relative to previous studies that did not focus specifically on the older population. Furthermore, the current project had a lower percentage (46\%) of residents with GERD as the sole indication for PPI therapy than did previous studies (78\%-
100\%). ${ }^{21,25}$ Previous studies have suggested that it is especially difficult to discontinue PPIs in patients with GERD. Björnsson and other ${ }^{21}$ noticed a positive correlation between the need to resume PPIs and GERD as the indication for PPI therapy. Therefore, the higher discontinuation success rate in the current study can be explained, at least in part, by the lower percentage of participants with GERD as the indication for PPI therapy. Even though the success rate was higher than achieved in previous studies, we cannot draw firm conclusions about the proportion of long-term PPI users in residential care settings who would be able to tolerate PPI deprescribing.

Some of the participants had a return of gastrointestinal symptoms after PPI discontinuation. These results are consistent with a previous study, in which GERD-related symptoms prompted resumption of PPIs earlier than non-GERD-related symptoms. ${ }^{21}$ In the current study, one participant resumed PPI therapy after 9 days because of heartburn and another resumed the PPI after 25 days because of acid reflux. For 2 other participants, PPI therapy was resumed or H2RA therapy initiated for non-GERD-related symptoms (after 27 days because of emesis and after 33 days because of vomiting, respectively). For all 4 of these participants, the PPI was restarted or H2RA initiated within 5 weeks of discontinuation, which is in keeping with other studies. ${ }^{23,31}$

With regard to dosing, all of the participants with PPI restarted or H2RA initiated had previously been taking pantoprazole or esomeprazole $40 \mathrm{mg} /$ day, which is considered the standard dose. We would expect that those receiving high-dose PPI therapy would be at greater risk of recurrent gastrointestinal symptoms. However, this expectation was not borne out, which could be attributable to the small sample size or the older population. These results highlight that people in residential care may experience rebound gastrointestinal symptoms. Therefore, tapering PPIs in the older population may be a more reasonable approach to discontinuation, both to prevent rebound gastrointestinal symptoms and to identify the lowest effective PPI dose. Further research about PPI discontinuation in the older population, using larger sample sizes, is needed to confirm the best approach.

Because the study design involved close monitoring of symptom recurrence (by 3 pharmacists, in collaboration with nurses, physicians, and the residents themselves), it was deemed reasonable to discontinue PPIs without tapering. The 3 pharmacists actively followed each resident weekly, and PPI or H2RA therapy was started promptly for any participant who was found to have gastrointestinal symptoms. This study has shown that close monitoring of PPI discontinuation is warranted to assess for recurrent gastrointestinal symptoms when PPIs are discontinued without tapering. Although there is currently a lack of good evidence for tapering PPIs and there is no clear consensus on how discontinuation should be attempted, ${ }^{1}$ the limited evidence 
This single copy is for your personal, non-commercial use only.

For permission to reprint multiple copies or to order presentation-ready copies for distribution, contact CJHP at cjhpedit@cshp.ca

available does support the existence of a withdrawal phenomenon. Tapering of PPI therapy seems to be more successful than abrupt discontinuation. ${ }^{1}$ A systematic review published in 2013 showed that in 3 of the 5 included studies (which were conducted in asymptomatic volunteers), rebound hypersecretion of gastric acid occurred after discontinuation of PPI therapy. ${ }^{32}$ Therefore, use of tapering as a PPI discontinuation strategy may prevent rebound hypersecretion and may increase patient comfort with deprescribing. Randomized controlled trials comparing various discontinuation strategies are needed.

\section{Limitations}

As a small quality improvement project, this study had several limitations. First, because the study was done at a residential care site, preadmission data were unknown. Therefore, the duration of each patient's PPI therapy could only be estimated. Second, this study involved a sample of 27 residents at a single care site, and it is unknown whether these results are generalizable to other residential care sites. Third, 3 pharmacists followed the residents weekly after PPI discontinuation to assess for symptom recurrence, so interobserver variation could not be excluded. Without a validated tool to determine symptom recurrence, this interobserver variation is a limitation that might have affected the number of residents restarted on PPIs, thus inadvertently affecting the overall study results. Fourth, baseline $H$. pylori results were not collected for the participants; therefore, it is unknown whether any of them had previously tested positive for $H$. pylori. Finally, the study had a short follow-up period of only 8 weeks. Although previous studies found that asymptomatic patients often experienced heartburn, acid regurgitation, and dyspepsia during the first 4 to 8 weeks after PPI discontinuation, ${ }^{21,22,24,33}$ there is a possibility that participants in the current study experienced return of GERD symptoms after the study ended.

\section{CONCLUSION}

The results of this study support PPI discontinuation for most people in residential care facilities who have been receiving this type of therapy for longer than 6 months and are not experiencing gastrointestinal symptoms. They have also provided some evidence to suggest that tapering can be used to identify the lowest effective dose and may increase patient comfort with deprescribing. Further research is needed to determine the effects of and best approaches to PPI discontinuation in older populations.

\section{References}

1. Haastrup P, Paulsen MS, Begtrup LM, Hansen JM, Jarbøl DE. Strategies for discontinuation of proton pump inhibitors: a systematic review. Fam Pract. 2014;31(6):625-30.

2. Bashford JN, Norwood J, Chapman SR. Why are patients prescribed proton pump inhibitors? Retrospective analysis of link between morbidity and prescribing in the General Practice Research Database. BMJ. 1998;317(7156):452-6.
3. Nardino RJ, Vender RJ, Herbert PN. Overuse of acid-suppressive therapy in hospitalized patients. Am J Gastroenterol. 2000;95(11):3118-22.

4. Pillans PI, Kubler PA, Radford JM, Overland V. Concordance between use of proton pump inhibitors and prescribing guidelines. Med J Aust. 2000 172(1):16-8.

5. Strid H, Simrén M, Björnsson ES. Overuse of acid suppressant drugs in patients with chronic renal failure. Nephrol Dial Transplant. 2003;18(3):570-5.

6. Ryder SD, O’Reilly S, Miller RJ, Ross J, Jacyna MR, Levi AJ. Long term acid suppressing treatment in general practice. BMJ. 1994;308(6932):827-30.

7. Heidelbaugh JJ, Goldberg KL, Inadomi JM. Magnitude and economic effect of overuse of antisecretory therapy in the ambulatory care setting. Am J Manag Care. 2010;16(9):e228-34.

8. Deshpande A, Pant C, Pasupuleti V, Rolston DDK, Jain A, Deshpande N, et al. Association between proton pump inhibitor therapy and Clostridium difficile infection in a meta-analysis. Clin Gastroenterol Hepatol. 2012; 10(3):225-33.

9. Janarthanan S, Ditah I, Adler DG, Ehrinpreis MN. Clostridium difficileassociated diarrhea and proton pump inhibitor therapy: a meta-analysis. $A m J$ Gastroenterol. 2012;107(7):1001-10.

10. Kwok CS, Arthur AK, Anibueze CI, Singh S, Cavallazzi R, Loke YK. Risk of Clostridium difficile infection with acid suppressing drugs and antibiotics: meta-analysis. Am J Gastroenterol. 2012;107(7):1011-9.

11. Tleyjeh IM, Bin Abdulhak AA, Riaz M, Alasmari FA, Garbati MA, AlGhamdi $\mathrm{M}$, et al. Association between proton pump inhibitor therapy and Clostridium difficile infection: a contemporary systematic review and meta-analysis. PLOS One. 2012;7(12):e50836.

12. Ngamruengphong S, Leontiadis GI, Radhi S, Dentino A, Nugent K. Proton pump inhibitors and risk of fracture: a systematic review and meta-analysis of observational studies. Am J Gastroenterol. 2011;106(7):1209-18; quiz 1219.

13. Clinical protocol: polypharmacy risk reduction in residential care. Surrey (BC): Fraser Health; [updated 2014 Sep 8; cited 2016 Jul 1]. Electronic resource accessed through institutional intranet.

14. American Geriatrics Society 2015 Beers Criteria Update Expert Panel. American Geriatrics Society 2015 updated Beers Criteria for potentially inappropriate medication use in older adults. J Am Geriatr Soc. 2015;63(11):2227-46.

15. Frazier SC. Health outcomes and polypharmacy in elderly individuals: an integrated literature review. J Gerontol Nurs. 2005;31(9):4-11.

16. Trygstad TK, Christensen D, Garmise J, Sullivan R, Wegner S. Pharmacist response to alerts generated from Medicaid pharmacy claims in a long-term care setting: results from the North Carolina polypharmacy initiative. J Manag Care Pharm. 2005;11(7):575-83.

17. Hanlon JT, Schmader KE, Koronkowski MJ, Weinberger M, Landsman PB, Samsa GP, et al. Adverse drug events in high risk older outpatients. J Am Geriatr Soc. 1997;45(8):945-8.

18. Lazarou J, Pomeranz BH, Corey PN. Incidence of adverse drug reactions in hospitalized patients: a meta-analysis of prospective studies. JAMA. 1998;279 (15):1200-5.

19. Gallagher P, Ryan C, Byrne S, Kennedy J, O’Mahony D. STOPP (Screening Tool of Older Person's Prescriptions) and START (Screening Tool to Alert doctors to Right Treatment). Consensus validation. Int J Clin Pharmacol Ther 2008;46(2):72-83.

20. Garfinkel D, Mangin D. Feasibility study of a systematic approach for discontinuation of multiple medications in older adults: addressing polypharmacy. Arch Intern Med. 2010;170(18):1648-54.

21. Björnsson E, Abrahamsson H, Simrén M, Mattsson N, Jensen C, Agerforz P, et al. Discontinuation of proton pump inhibitors in patients on long-term therapy: a double-blind, placebo-controlled trial. Aliment Pharmacol Ther. 2006 24(6):945-54.

22. Murie J, Allen J, Simmonds R, de Wet C. Glad you brought it up: a patientcentred programme to reduce proton-pump inhibitor prescribing in general medical practice. Qual Prim Care. 2012;20(2):141-8.

23. Reimer C, Bytzer P. Discontinuation of long-term proton pump inhibitor therapy in primary care patients: a randomized placebo-controlled trial in patients with symptom relapse. Eur J Gastroenterol Hepatol. 2010;22(10):1182-8.

24. Zwisler JE, Jarbøl DE, Lassen AT, Kragstrup J, Thorsgaard N, Schaffalitzky de Muckadell OB. Placebo-controlled discontinuation of long-term acidsuppressant therapy: a randomised trial in general practice. Int J Family Med. 2015;2015:175436. 
This single copy is for your personal, non-commercial use only.

For permission to reprint multiple copies or to order presentation-ready copies for distribution, contact CJHP at cjhpedit@cshp.ca

25. Inadomi JM, Jamal R, Murata GH, Hoffman RM, Lavezo LA, Vigil JM, et al. Step-down management of gastroesophageal reflux disease. Gastroenterology. 2001;121(5):1095-100.

26. Linsky A, Hermos JA, Lawler EV, Rudolph JL. Proton pump inhibitor discontinuation in long-term care. J Am Geriatr Soc. 2011;59(9):1658-64.

27. Thompson W, Hogel M, Li Y, Thavorn K, O'Donnell D, McCarthy L, et al. Effect of a proton pump inhibitor deprescribing guideline on drug usage and costs in long-term care. J Am Med Dir Assoc. 2016;17(7):673.e1-4.

28. Proton pump inhibitor (PPI) deprescribing algorithm. Ottawa $(\mathrm{ON})$ : Deprescribing.org; 2015 [cited 2016 Jul 1]. Available from: www.openpharmacy-research.ca/wordpress/wp-content/uploads/ppi-deprescribingalgorithm-cc.pdf

29. Farrell B, Pottie K, Rojas-Fernandez CH, Bjerre LM, Thompson W, Welch V. Methodology for developing deprescribing guidelines: using evidence and GRADE to guide recommendations for deprescribing. PLoS One. 2016; 11(8):e0161248.

30. Fass R, Pulliam G, Johnson C, Garewal HS, Sampliner RE. Symptom severity and oesophageal chemosensitivity to acid in older and young patients with gastro-oesophageal reflux. Age Ageing. 2000;29(2):125-30.

31. Niklasson A, Lindström L, Simrén M, Lindberg G, Björnsson E. Dyspeptic symptom development after discontinuation of a proton pump inhibitor: a double-blind placebo-controlled trial. Am J Gastroenterol. 2010;105(7):1531-7.

32. Lødrup AB, Reimer C, Bytzer P. Systematic review: symptoms of rebound acid hypersecretion following proton pump inhibitor treatment. Scand J Gastroenterol. 2013;48(5):515-22.

33. Coté GA, Ferreira MR, Rozenberg-Ben-Dror K, Howden CW. Programme of stepping down from twice daily proton pump inhibitor therapy for symptomatic gastro-oesophageal reflux disease associated with a formulary change at a VA medical center. Aliment Pharmacol Ther. 2007;25(6):709-14.
Candy Lee, BScPharm, is a Pharmacist with Ridge Meadows Hospital, Maple Ridge, British Columbia.

Anita Lo, BScPharm, PharmD, is a Clinical Pharmacy Specialist with Baillie House, Ridge Meadows Hospital, Maple Ridge, British Columbia.

Kiran Ubhi, BSP, PharmD, is a Clinical Pharmacy Specialist with Baillie House, Ridge Meadows Hospital, Maple Ridge, British Columbia.

Michael Milewski, MD, is the Medical Director at Baillie House, Ridge Meadows Hospital, Maple Ridge, British Columbia.

Competing interests: None declared.

\section{Address correspondence to:}

Candy Lee

11666 Laity Street

Maple Ridge BC V2X 5A3

e-mail: Candy.lee@fraserhealth.ca

Funding: None received.

Acknowledgement: The authors would like to thank Samar Hejazi, epidemiologist at Fraser Health Authority, for help with this project. 